\title{
Research on the Impact of Live Video Streaming on Customers' Consumption Behavior and Intention
}

\begin{abstract}
Yan Yang ${ }^{1, *}$
${ }^{1}$ Department of Management, College of Business, University of Nebraska-Lincoln, Lincoln, NE 68588, US

"Corresponding author.Email: y2312787291@ hotmail.com

ABSTRACT

Many merchants increasingly use live video streaming to sell their products to increase sales and promote their brands, which has created huge profits for them. Therefore, this paper will focus on customers' consumption behavior and intention on this platform. This research takes 50 people with shopping experience on living streaming platforms as the research object and adopts the research online questionnaires to analyze their consumption characteristics and consumption tendency. The results show that most of the products purchased by respondents through live shopping are food, followed by beauty products. The reason why they choose to place an order is that the discount on the product attracts them. Product display also makes an influence of their choice. However, they are not satisfied with the products purchased through the webcast. In addition, based on the SOR (Stimulus, Organization, Response) theory, this paper constructs a logical model of the impact of webcasts on consumers' purchase intention through literature analysis.
\end{abstract}

Keywords: living video streaming, consumption behavior and intention, webcasts, consumption

characteristics

\section{INTRODUCTION}

With the rapid development of the mobile network and the popularity of intelligent devices', network live broadcast has become the focus of public's attention. Besides, due to COVID-19, consumers pay more attention to online shopping. As of June 2020, the number of Internet users in China has reached 940 million, with 28.0 hours of online time per week per capita, of which $7.3 \%$ are live webcast applications; 562.3 million live webcast users are mainly young people.[1] It can be seen that the significant number of Internet users has become the fundamental guarantee for realizing the scale effect of live broadcasting with goods.

Various scenes and strong interactive experience provide a new way for enterprises to show their products, brands, and images more vividly. Enterprises take advantage of the efficient, timely, and low-cost advantages of Internet information transmission to gradually develop a webcast marketing model. The realtime network has more and more extensive and profound influence on consumer behavior.

\section{RESEARCH AND METHODOLOGY}

This research adopts the method of a questionnaire survey to explore and analyze the influence of online live broadcast on consumers' purchase behavior and purchase intention. The research object is mainly young people who have the experience of watching live streaming and placing orders on living streaming platforms. A total of 50 valid questionnaires are collected, of whom $37.25 \%$ are males and $62.75 \%$ are females. The number of young consumers accounts for $78.43 \%$.

There are 15 questions in the questionnaire:

- What's your gender?

- What's your age?

- What is your monthly consumption level?

- How often do you watch live streaming?

- What are the reasons that make you decide to buy in the live streaming? (MCQ)

- What is in your mind when you have no target consumption?

- What kind of products do you often buy through the live streaming? (MCQ)

- What is the main basis for you to decide to buy the product?

- Do the following options match your buying behavior when watching the live broadcast? 
A. I have a lot of things I bought while watching the live streaming but I rarely use them in the near future.

B. I rarely buy items outside the plan while watching live streaming.

C. I'm always impulsive when placing an order.

D. When I watch the live broadcast, the actual consumption amount always exceeds expectations

- Please review your recent experience of placing an order while watching live streaming and make your choice according to your actual situation.

- Do you have any experience of returning products after placing an order online?

- What is the reason for you to return the products after you purchase them?
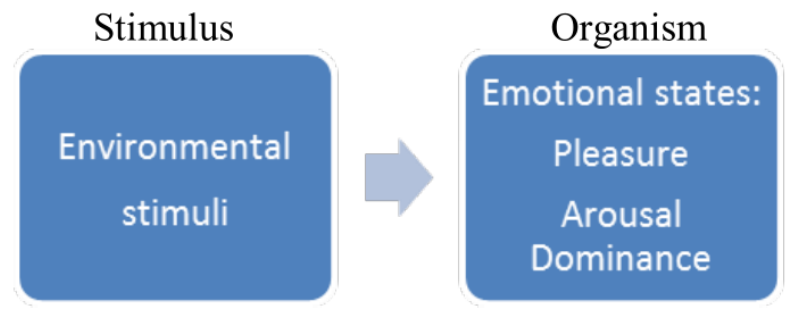

Fig. 1. S-O-R model.

SOR theory refers to Stimulus, Organism and Response ("Fig. 1"), which is a general pattern of human behavior. This model shows that consumers' purchase behavior is caused by stimulation, which comes from consumers' physiological and psychological aspects and the external environment. Under the stimulation of various factors, consumers generate motivation and make purchase decisions.

Recently, many scholars adopt SOR theory to study consumer behavior. It can also be used in the study of consumers' purchase intention. As an external stimulus, online live shopping can also stimulate consumers to produce emotional or cognitive reactions and then generate consumption behavior. Therefore, this study believes that SOR theory is also applicable to the study of online live shopping.

Donovan \& Rossiter firstly applied S-O-R model to the retail environment to study the influence of the retail environment atmosphere on consumers' purchase behavior[2]. Based on the SOR model, Lu Yang studied consumers' purchase intention in the online shopping environment[3]. The results show that the better the atmosphere and image of the online store and the higher the perceived quality, the stronger the consumer's willingness to buy. Zhao applied the model to the study of online consumers' impulsive buying[4]. The results show that website environmental factors can indirectly

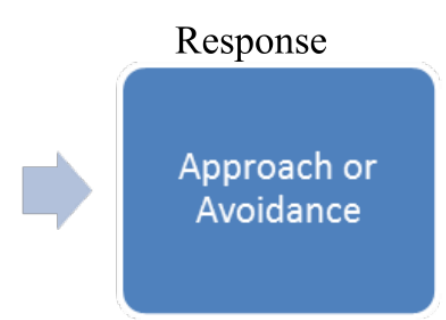

- What is your solution when you are not satisfied with the product?

- Before purchasing, which of the following situations does your mobile order have?

Attracted by product promotion $\rightarrow$ be interested in the product $\rightarrow$ search for the product

Because of a certain demand $\rightarrow$ search for this type of product $\rightarrow$ become interested in the product

Recommend by others $\rightarrow$ become interested in the product $\rightarrow$ search for the product

Browse without purpose.

- Please use the number $(0 \sim 10)$ to measure your feeling of live consumption. affect consumers' impulsive buying behavior through influencing consumers' emotions.

\section{ANALYSIS}

In this survey, $37.25 \%$ of the respondents are males, $62.75 \%$ are females, and $78.43 \%$ are from 18 to 25 years old. According "Fig. 2", $76.47 \%$ of the respondents carry out live shopping once a week.

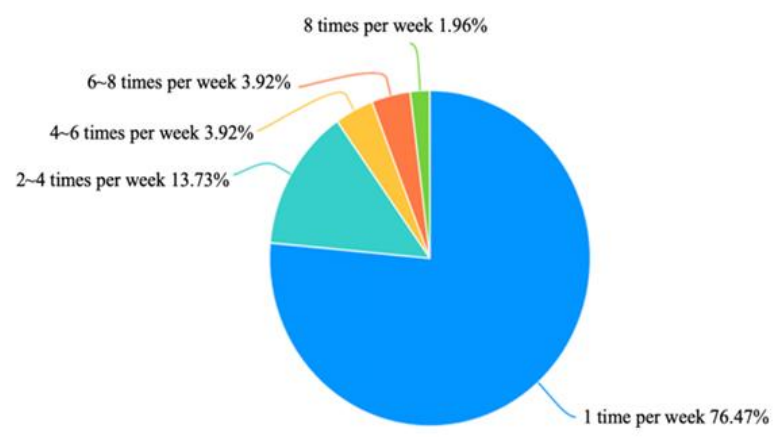

Fig. 2. Number of times customers watch live streaming per week 


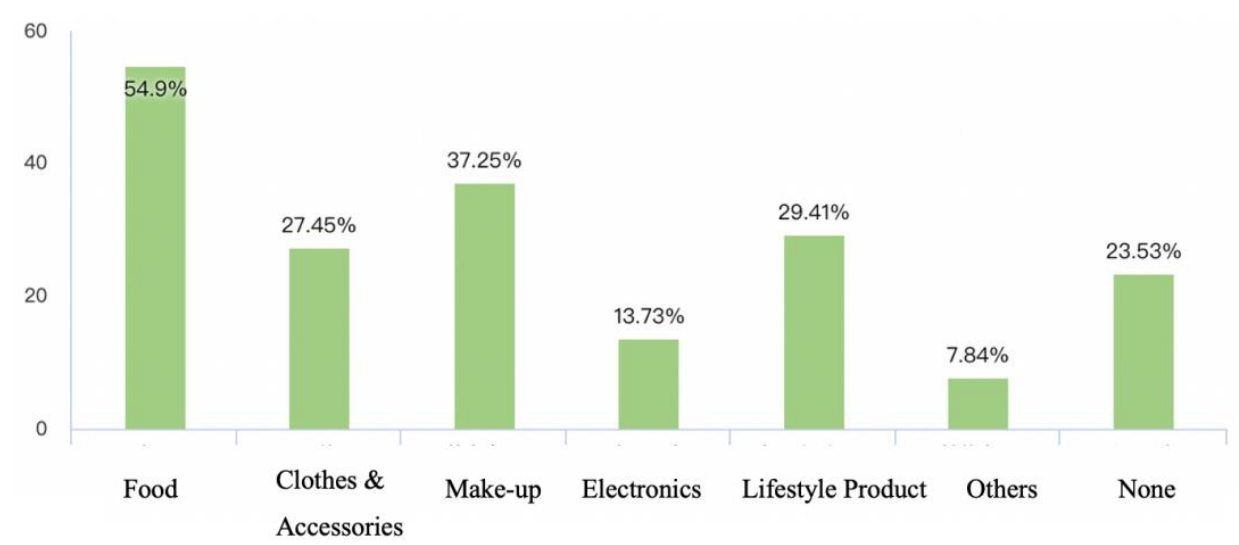

Fig. 3. Product category.

It can be seen from "Fig. 3" that most of the categories purchased by consumers in live e-commerce are clothing, daily necessities, gourmet food, and beauty

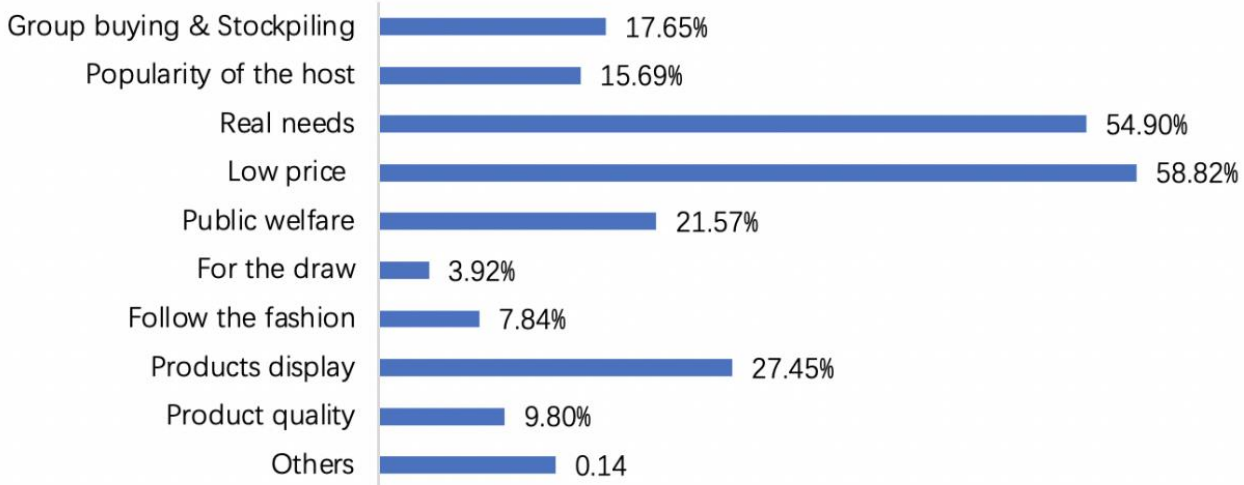

Fig. 4. Factors that encourage customers to place orders.

The two bar charts illustrate the type of products the respondents prefer to buy and factors that encourage them to place orders while watching live video streaming. As is shown in the graphs, more than half of the respondents buy food and beauty products, followed by daily necessities which is $29.41 \%$. From "Fig. 4", real needs $(54.90 \%)$, low price $(58.82 \%)$, and product display $(27.45 \%)$ are the three main reasons to attract customers to place orders.

Through the analysis of the data, more than half of the respondents think that they are impulsive when buying products. Jacob [5] argued that consumer behavior is caused by the stimulation of external factors, which leads to some emotional or cognitive reaction and then leads to the consumption behavior of tendency or avoidance. For example, the host will design interesting themes, and the shopping platform will also carry out a series of reward activities, such as issuing coupons or lottery [6]. It can be seen from the cosmetics, and the consumers who buy food are the most, accounting for $54.9 \%$. 


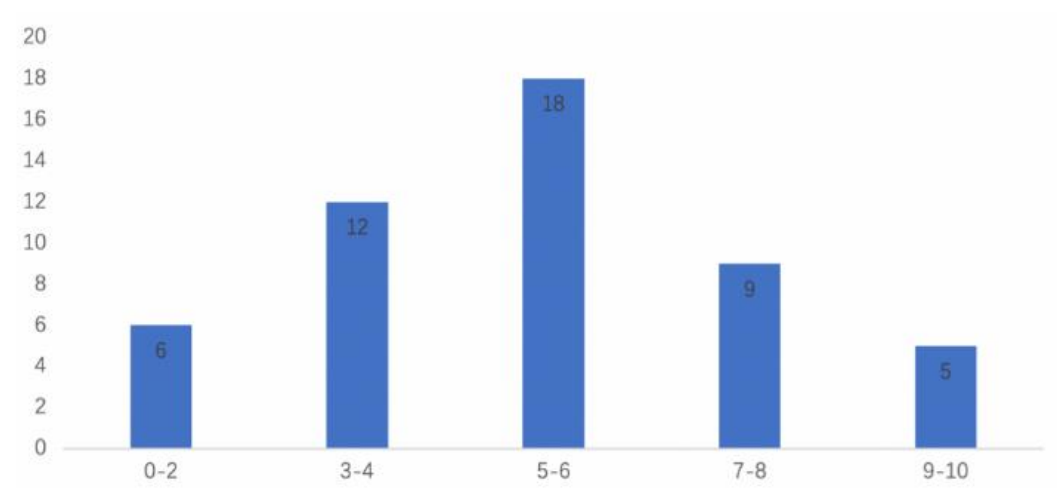

Fig. 5. Customer satisfaction of live shopping.

"Fig. 5" shows the satisfaction of customers shopping live. Among them, the horizontal axis is satisfaction (total score is 10 points), and the vertical axis is the number of people. We can see that there are 36 people below 6 points. According to the data, the respondents' overall perceived satisfaction with the live streaming is not high. Therefore, it is significant to note that there is still a large room for the live-streaming industry to improve. Consumers will check whether the purchased products are the same as they expected before purchase. Satisfaction directly affects whether they will continue to consume in the future.
Nowadays, for the sake of consumers' worry-free shopping, most brands will launch a seven-day return or exchange without any reason and strengthen the aftersales service of consumers. Consumers can communicate with relevant service personnel if they have any questions after shopping. This approach increases consumer satisfaction and trust and maximizes consumer security, which makes consumers more willing to choose the goods that they need in this relaxed and pleasant environment.

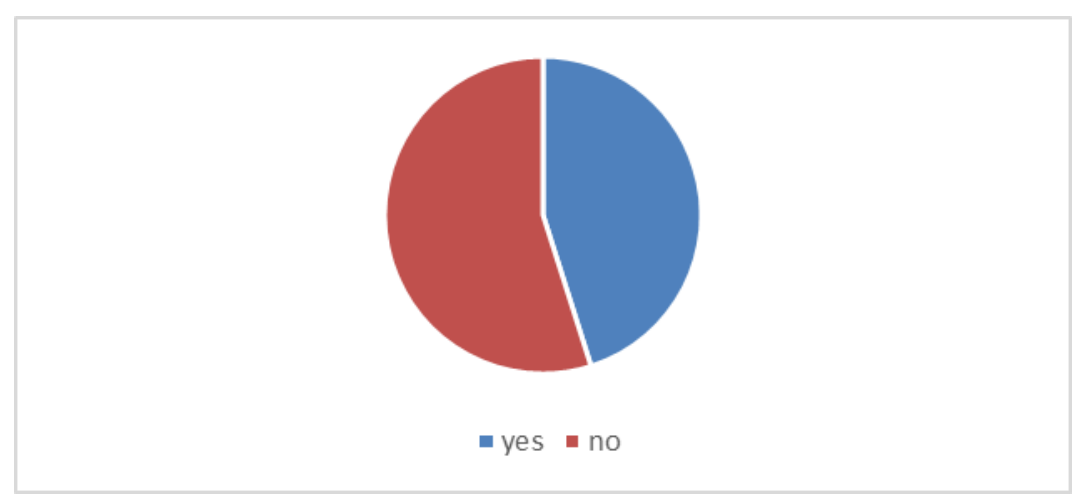

Fig. 6. The experience of returning the products.

It is found from "Fig. 6" that $45.1 \%$ of consumers have returned goods in live shopping, mostly due to the product quality and the reasons not in line with the actual situation. After further investigation on the consumers who have not complained about the problems, it could be seen that nearly half of the consumers give up their complaints because of the lower price; the more prominent reason is that the complaint handling process may be complicated or time-consuming. To some extent, it also shows that consumers are lack patience and confidence in safeguarding their legitimate rights and interests.

\section{RECOMMENDATIONS}

Based on the above analysis, in order to improve the degree of consumer satisfaction, some reference suggestions are put forward for the stakeholders involved in the mode of live commerce.

The essence of this new marketing model is still inseparable from the sale of goods. Therefore, the quality factors that consumers pay attention to become the critical content of improving the degree of consumer satisfaction to reduce the probability of consumers returning goods.

Besides, the anchor should take effective interactive methods in combination with the types of goods sold, 
and lead consumers to actively communicate in the interaction, to stimulate emotional reaction and enhance perceived trust; the authenticity of commodities should be fully restored, and the emotional response and confidence of consumers should be improved in the process of commodity display.

The platform and merchants should design the shopping scene pertinently and display the characteristics of goods from all aspects and angles. As consumers can intuitively feel the live broadcast room environment when shopping online, to improve consumers' shopping experience in the live broadcast room, businesses or platforms should construct a good environment of the live broadcast room to enhance the shopping comfort of consumers.

\section{CONCLUSION}

This study adopts questionnaires to explore the impact of live video streaming on customers' consumption behavior and intention. Besides, based on the SOR theory and the analysis of the survey data, in addition to the product quality, product display and the affection of interaction between hosts and consumers will also have a significant impact on consumer purchase behavior and willingness.

On the other hand, online live shopping enriches consumers' purchase options, provides consumers with a new consumption experience, and further promotes economic development after the epidemic. But inevitably, due to the increasing number of adverse events caused by live online shopping, relevant departments should put forward corresponding measures to promote the healthy and correct development of live commerce.

\section{References}

[1] China Internet Network Information Center. The 46th statistical report on China's Internet development [EB / OL] (2020-09-29) http://www.cac.gov.cn/2020-09/29/c_1602939918747816.htm

[2] Donovan R J, Rossiter J R. Store atmosphere: an environmental psychology approach [J]. Journal of Retailing, 1982, 58(1): 3457.

[3] Yang Lu. The influence of online store atmosphere on consumers' purchase intention. Business Research (11), 2009: 214-216.

[4] Zhao Yuna. Research on the Influence of Website Environment Characteristics on Consumer's Impulse Buying, 2010.

[5] Jacob. Stimulus-Organism-Response Reconsidered: An Evolutionary Step in Modeling Consumer Behavior [J]. Journal of Consumer Psychology,2002,12(1):51-57.

[6] Ma H, Mei H.Empirical Research on the Decision-Making Influence Factors in Consumer Purchase Behavior of Webcasting Platform [J]. International Conference on Management Science and Engineering Management,2018(6):1017-1028. 